AOGS MAIN RESEARCH ARTICLE

\title{
Non-medical determinants of cesarean section in a medically dominated maternity system
}

\author{
DIÁNA DWEIK ${ }^{1}$, EDMOND GIRASEK ${ }^{2}$, GYULA MÉSZÁROS ${ }^{1}$, ANNAMÁRIA TÖREKI ${ }^{1}$, ATTILA \\ KERESZTÚRI ${ }^{1}$ \& ATTILA PÁL ${ }^{1}$ \\ ${ }^{1}$ Department of Obstetrics and Gynecology, University of Szeged, Szeged, and ${ }^{2}$ Health Services Management Training \\ Centre, Semmelweis University, Budapest, Hungary
}

\section{Key words}

Childbirth preference, mode of delivery, questionnaire, principal component analysis, fear of childbirth

\section{Correspondence}

Diána Dweik, Department of Obstetrics and Gynecology, University of Szeged,

Semmelweis u. 1, H-6725 Szeged, Hungary.

E-mail: ddinji@yahoo.com

\section{Conflict of interest}

The authors alone are responsible for the content and writing of this article. The authors have stated explicitly that there are no conflicts of interest in connection with this article.

Please cite this article as: Dweik D, Girasek E, Mészáros G, Töreki A, Keresztúri A, Pál A. Non-medical determinants of cesarean section in a medically dominated maternity system. Acta Obstet Gynecol Scand 2014; 93: 1025 1033.

Received: 4 April 2014

Accepted: 17 July 2014

DOI: 10.1111/aogs.12466

\begin{abstract}
Objective. To assess the contribution of non-medical factors to actual mode of delivery in a setting with high cesarean rates. Design. Follow-up survey. Setting. University department of obstetrics and gynecology. Sample. Women with singleton pregnancies $(n=453)$ where there was no awareness of medical contradictions to vaginal delivery, attending for routine mid-pregnancy ultrasound examination in November 2011 to March 2012, and delivering between March and August 2012. Methods. Structured questionnaire completed in gestational weeks 18-22. Information on subsequent delivery was obtained from patient files and through personal contact. Main outcome measures. Contribution of childbirth preference, Wijma Delivery Expectancy/Experience Questionnaire A score, socio-demographic characteristics, attitudes toward birth issues and circumstances of pregnancy/delivery to mode of delivery. Results. The majority of respondents $(410 / 453 ; 90.5 \%)$ preferred vaginal delivery; nevertheless, one-third (two-fifths of nulliparas) had a cesarean delivery. Among nulliparous respondents, a longer perceived interval from decision for pregnancy to conception, lower importance assigned to personal control, and the presence of an obstetrician with power to decide about cesarean delivery, were independent contributors to the binary logistic regression model explaining higher maternal cesarean risks. For parous respondents, corresponding factors were younger maternal age, perceived environmental influence towards cesarean section, the respondent's belief that cesarean is more beneficial than vaginal delivery and an older obstetrician attending the delivery. Conclusions. The results of this questionnaire survey contribute to the already existing evidence that against the background of high cesarean rates, non-medical factors, as much related to the obstetricians as to pregnant women's attitudes, play an important role.
\end{abstract}

Abbreviations: CS, cesarean section; FOC, fear of childbirth; VD, vaginal delivery; W-DEQ A, Wijma Delivery Expectancy/Experience Questionnaire A.

\section{Introduction}

The cesarean section (CS) rate in Hungary is one of the highest in Europe and it has shown a threefold rise since the late 1980s, reaching $33.3 \%$ in 2012 (1). Domestic and international debate concerning the reasons for this epidemic have highlighted numerous contributors to this trend: less risky procedures due to medical developments, remarkable demographic changes in the pregnant population, widening of the range of indications for CS that has shifted the formerly life-saving character of the procedure towards a perceived preventive spectrum, and a threatening medico-legal environment that has pushed obstetricians into defensive acts (2-4). Beside these factors, the possible role of openly expressed and irrefutable demands 
of pregnant women has also emerged $(3,5)$, launching a new generation of studies investigating the attitudes, beliefs, preferences, needs and fears of expectant mothers. Many of these studies, however, instead of affirming the assumption that large numbers of women are in favor of CS, called attention to other issues possibly contributing to rising CS rates, such as fear of childbirth (FOC), inadequacy of the information-giving process, convenience and financial incentives for physicians, and anomalies of different maternity care systems, including women's limited access to midwifery care or their fears of receiving substandard maternity care (6-12). The widespread notion of obstetricians' respect for patient autonomy was also challenged by some studies (9,11-13).

Our assumption that at least a few of the above-mentioned anomalies, apart from certain cross-cultural differences, also characterize the Hungarian obstetric setting, is based on the relatively high CS rate, the long tradition of medical dominance in maternity care, and the overlap of private and public health care that is mediated by informal payments $(14,15)$. As the Hungarian College of Obstetricians and Gynecologists was against CS on maternal request in its 2003 statement (16), there is no legal option in Hungarian public health care to deliver by CS in the absence of a firm medical indication. Thus, any investigation of the indications for abdominal delivery from official patient files would certainly mask, or not unveil, possible non-medical determinants of the rising CS rate.

The aim of this study was to determine the extent to which non-medical factors contribute to the actual mode of delivery of women in a Hungarian tertiary referral obstetric unit, by investigating pregnant women's socio-demographic characteristics, their mid-pregnancy Wijma Delivery Expectancy/Experience Questionnaire A (W-DEQ A) scores, their attitudes and childbirth preferences. We also wanted to cast light on the possible role of organizational issues (staffing, timing) related to the subsequent obstetric outcome.

\section{Material and methods}

As a part of a broader observational longitudinal perinatal questionnaire survey, this follow-up survey aimed to assess the contribution of certain non-medical factors, present before pregnancy, in mid-pregnancy and at the time of delivery to the actual mode of delivery. The survey was approved by the Human Investigation Review Board, University of Szeged, Albert Szent-Györgyi Clinical Center (No. 114/2011, 12.09., 2011).

Based on the criteria for selection, pregnant women in gestational weeks 18-22 were recruited at the ultrasound laboratory of the Department of Obstetrics and Gynecol- ogy, University of Szeged, Hungary, between November 2011 and March 2012 when they presented for their second trimester routine ultrasound examination. Women who were under 18 years of age or had legal incapacity, those who were illiterate or did not read/write Hungarian were excluded. Pregnant women at high risk (including multiple gestations) and those who had any medically justified condition which contraindicated vaginal delivery (VD) were also excluded. After informing the women about the aims and course of the survey, written consent was obtained from $503(97.5 \%)$ of the 516 eligible women. A total of 488 women (94.6\%) fully answered the questionnaires and data from them were used in our statistical analysis [reasons for drop-out were detailed in our previous article (15)].

The questionnaire consisted of three main parts (A, B and C). Part A addressed birth preference ("Which way would you prefer to deliver your baby if the decision was up to you? VD or CS?") and maternal attitudes toward pregnancy and childbirth issues using 33 statements, each followed by a 6-point Likert scale (ranging from $0=I$ do not agree at all, to $5=I$ absolutely agree). Part B involved the Hungarian translation (with permission) of Wijma Delivery Expectancy/Experience Questionnaire A (17), a tool aimed to quantify antenatal level of FOC. We applied crude W-DEQ A scores in the analysis and did not use the special nomenclature of FOC. In Part C, basic sociodemographic and obstetric history data of the women were collected. More detailed information about the questionnaire can be found in our previous article (15).

Information on obstetric outcome of those delivering in the department $(n=446)$ was gained through personal contact and from patient files. Of those who delivered in another hospital, seven women responded to our query regarding factual data on their delivery by post or e-mail. Thus, altogether 453 (87.8\%) women's questionnaires and obstetric outcome data were analyzed. Besides mode of delivery the following supplementary obstetric outcome

\section{Key Message}

A majority of pregnant women in this Central European setting preferred in mid-pregnancy to give birth vaginally; however, one-third of them eventually had a cesarean section. Multivariate analysis did not suggest that the women's mid-pregnancy childbirth preferences or higher W-DEQ A scores contributed to the delivery outcome but, instead, other non-medical factors related to women's attitudes and doctors who were supposed to follow the course of labor and delivery had a significant impact. 
data were obtained: gestational age at delivery, time of day and day of week of delivery, age and gender of the attending obstetrician, if he/she was the patient's private obstetrician, and whether he/she had the power to decide upon CS. This latter variable had two dimensions: obstetricians who were experienced enough formed one group and the less experienced doctors, who had to ask for a second opinion before recommending CS, formed another.

\section{Statistical analysis}

Statistical analysis was performed by using IBM SPSS Statistics Version 20.0 (Armonk, NY, USA). Principal com- ponent analysis was used to group maternal attitudes toward childbirth issues, according to our initial hypothesis regarding distinct dimensions of attitudes. Eight principal components were extracted from 32 of the 33 attitude variables by this method (Table 1). Cronbach's alpha of the averaged attitude variables was acceptable at 0.694 (18). One dichotomous variable was created from the variable regarding childbirth preference: respondents either not answering the question or expressing ambiguity and those with explicit preference for CS composed one group vs. women preferring VD. Bivariate correlation between childbirth preference, W-DEQ A scores and mode of delivery were assessed by the chi-square test and independent-sample $t$-test. Mode of delivery was then

Table 1. Principal components built up of 32 attitude variables.

\begin{tabular}{|c|c|c|}
\hline Principal components & Attitude variables & $\begin{array}{l}\text { Component } \\
\text { weight }^{\mathrm{a}}\end{array}$ \\
\hline \multirow[t]{3}{*}{ "Being in control" } & I feel that I know almost nothing about what will happen to me on the day of my delivery. & 0.600 \\
\hline & It is hard for me to cope with uncertainty. & 0.715 \\
\hline & The concept of general anesthesia frightens me. & 0.636 \\
\hline \multirow[t]{2}{*}{ "Right to autonomy" } & $\begin{array}{l}\text { I believe that I have the right to make decisions regarding my body and to choose the way I } \\
\text { want to deliver my baby. }\end{array}$ & 0.779 \\
\hline & You cannot force a woman to be delivering vaginally. & 0.779 \\
\hline \multirow{4}{*}{$\begin{array}{l}\text { "In close contact with } \\
\text { the newborn" }\end{array}$} & I am looking forward to holding my baby in my arms right after delivery. & 0.645 \\
\hline & It is very important for me to be able to take care of my baby as soon as possible after delivery. & 0.707 \\
\hline & I would like to breastfeed. & 0.586 \\
\hline & I would like to experience the moment when my baby is born. & 0.591 \\
\hline \multirow[t]{4}{*}{ "Trust in the natural way" } & I trust my body's implicit knowledge. & 0.772 \\
\hline & I would like to have a delivery as natural as possible. & 0.661 \\
\hline & I feel that everything will be all right with delivery. & 0.675 \\
\hline & I would be very disappointed if I had to deliver by CS. & 0.334 \\
\hline \multirow[t]{4}{*}{ "Environmental influence" } & I have heard many terrible birth stories of family members and friends. & 0.265 \\
\hline & My doctor convinced me that CS is the most adequate way for me to deliver my baby. & 0.742 \\
\hline & Acquaintances and friends of mine recommend CS. & 0.782 \\
\hline & $\begin{array}{l}\text { My partner/my family members are worried about what could happen to me and my baby } \\
\text { during VD. }\end{array}$ & 0.786 \\
\hline \multirow{6}{*}{$\begin{array}{l}\text { "CS is more beneficial } \\
\text { than VD" }\end{array}$} & I believe that CS is the safer way for my baby to be delivered. & 0.804 \\
\hline & In my opinion, it is better for a child to be born vaginally. & -0.775 \\
\hline & I am worried about my sexual life being spoilt after VD. & 0.564 \\
\hline & I am worried that urinary incontinence will develop after VD. & 0.470 \\
\hline & CS is a simple and easy way of delivery. & 0.674 \\
\hline & $\begin{array}{l}\text { I believe that being born vaginally is very important for the healthy psychological development } \\
\text { of my baby. }\end{array}$ & -0.720 \\
\hline \multirow{5}{*}{$\begin{array}{l}\text { "Expectations toward } \\
\text { maternity care" }\end{array}$} & I have had many bad experiences about health care. & 0.669 \\
\hline & I am sure that I will receive the best care during labor and delivery. & -0.738 \\
\hline & I fear that I will be defenseless during labor and delivery. & 0.568 \\
\hline & I absolutely trust the judgment of obstetricians. & -0.740 \\
\hline & I would like to discuss many issues with the doctor but I feel that he is always short of time. & 0.619 \\
\hline \multirow[t]{4}{*}{ "VD, the object of fear" } & I am worried that labor and delivery will be very exhausting. & 0.770 \\
\hline & I am worried that I will not be able to cope with labor pain. & 0.848 \\
\hline & I am worried that I will not be in control during labor and delivery. & 0.865 \\
\hline & I am worried that I will not be able to deliver my baby. & 0.697 \\
\hline
\end{tabular}

$C S$, cesarean section; VD, vaginal delivery.

aprincipal component analysis. 
explained by binary logistic regression models built up by the forward conditional variable selection method (15). Goodness-of-fit (Nagelkerke $R^{2}$ ) value is the proportion of heterogeneity of mode of delivery explained by the independent variables in the model. The logistic regression method selected among the following independent variables: childbirth preference, principal component variables created from attitude variables, W-DEQ A score, main socio-demographic and obstetric history data, and supplementary obstetric outcome data.

\section{Results}

The most important socio-demographic and obstetric history data of nulliparous and parous respondents derived in mid-pregnancy are shown in Table 2. Parous women were older, had more obstetric complications previously and were more likely to be married than their nulliparous counterparts. Almost one-quarter of parous women had previous CS $(n=51,23.6 \%)$. Table 3 shows mid-pregnancy childbirth preferences and W-DEQ A scores of nulliparous and parous respondents. Altogether, nine of 10 respondents $(n=410,90.5 \%)$ would have chosen VD given the choice. Nulliparous women had higher W-DEQ A scores than their parous counterparts.

With regard to obstetric outcome, no deliveries took place beyond gestational week 42 , but there was preterm delivery in $4.4 \%$ of the cases $(n=20)$. Eight nulliparous women $(1.8 \%)$ had assisted VD, and one-third of respondents $(n=151)$, significantly more nulliparous $(n=95$; $40.1 \%)$ than parous $(n=56 ; 25.9 \%)$ women, had CS $(p=0.001)$. Of those not delivering vaginally, $15(9.9 \%)$ went through elective CS, $93(61.6 \%)$ had intrapartum CS, and $43(28.5 \%)$ had a non-elective operation without effectively starting to labor. Vaginal birth after cesarean rate in this sample was 10/51 (two of these women had already gone through vaginal birth after cesarean at the end of their previous pregnancies). Almost three quarters (41/56) of parous women who delivered by CS this time, had CS previously. Table 4 shows subsequent mode of delivery and how it was related to mid-pregnancy childbirth preference and W-DEQ A score. A significant correlation was detected only in the case of parous women: two-thirds of those delivering by CS preferred VD previously, whereas those delivering vaginally had lower W-DEQ A scores.

Supplementary obstetric outcome data regarding the time of delivery and the attending obstetrician are shown in Table 5. No significant difference was detected between nulliparous and parous respondents by bivariate analysis except for the weekday of delivery. Most deliveries took place during working hours, and there were almost twice as many deliveries on Friday than on Saturday, with an
Table 2. Main socio-demographic characteristics and obstetric history data of nulliparous and parous respondents in mid-pregnancy.

\begin{tabular}{|c|c|c|c|c|c|}
\hline & \multicolumn{2}{|c|}{$\begin{array}{l}\text { Nulliparous } \\
n=237\end{array}$} & \multicolumn{2}{|c|}{$\begin{array}{l}\text { Parous } \\
n=216\end{array}$} & \multirow[b]{2}{*}{ Significance } \\
\hline & $n$ & $\%$ & $n$ & $\%$ & \\
\hline \multicolumn{6}{|l|}{ Age (years) } \\
\hline $18-25$ & 62 & 26.2 & 22 & 10.2 & \multirow[t]{4}{*}{$p<0.001$} \\
\hline $26-30$ & 105 & 44.3 & 61 & 28.2 & \\
\hline $31-35$ & 51 & 21.5 & 94 & 43.5 & \\
\hline$>36$ & 19 & 8 & 39 & 18.1 & \\
\hline \multicolumn{6}{|l|}{ Civil status } \\
\hline Married & 110 & 46.4 & 148 & 68.5 & \multirow[t]{3}{*}{$p<0.001$} \\
\hline Cohabiting & 120 & 50.6 & 62 & 28.7 & \\
\hline $\begin{array}{l}\text { Living separately } \\
\text { from partner }\end{array}$ & 7 & 3 & 6 & 2.8 & \\
\hline \multicolumn{6}{|l|}{ Place of residence } \\
\hline Urban & 173 & 73 & 161 & 74.5 & \multirow[t]{2}{*}{$p=0.710$} \\
\hline Non-urban & 64 & 27 & 55 & 25.5 & \\
\hline \multicolumn{6}{|l|}{ Level of education } \\
\hline$\leq 11$ years & 41 & 17.3 & 47 & 21.8 & \multirow[t]{2}{*}{$p=0.231$} \\
\hline$>11$ years & 196 & 82.7 & 169 & 78.2 & \\
\hline \multicolumn{6}{|c|}{ Self-rated financial status } \\
\hline Below average & 52 & 21.9 & 42 & 19.4 & \multirow[t]{3}{*}{$p=0.770$} \\
\hline Average & 153 & 64.6 & 146 & 67.6 & \\
\hline Above average & 32 & 13.5 & 28 & 13 & \\
\hline \multicolumn{6}{|l|}{ Planned pregnancy } \\
\hline Yes & 206 & 86.9 & 179 & 82.9 & \multirow[t]{2}{*}{$p=0.228$} \\
\hline No & 31 & 13.1 & 37 & 17.1 & \\
\hline \multicolumn{6}{|c|}{ Perceived decision-to-conception interval } \\
\hline$\leq 6$ months & 156 & 65.8 & 150 & 69.4 & \multirow[t]{2}{*}{$p=0.411$} \\
\hline$>6$ months & 81 & 34.2 & 66 & 30.6 & \\
\hline \multicolumn{6}{|c|}{ Mode of fertilization } \\
\hline Spontaneous & 230 & 97 & 214 & 99.1 & \multirow[t]{2}{*}{$p=0.180^{b}$} \\
\hline Assisted & 7 & 3 & 2 & 0.9 & \\
\hline \multicolumn{6}{|c|}{ Tobacco habits during pregnancy } \\
\hline Non-users & 218 & 92 & 205 & 94.9 & \multirow[t]{2}{*}{$p=0.211$} \\
\hline Users & 19 & 8 & 11 & 5.1 & \\
\hline \multicolumn{6}{|c|}{ Complications in obstetric history ${ }^{c}$} \\
\hline Yes & 20 & 8.4 & 34 & 15.7 & \multirow[t]{2}{*}{$p=0.017$} \\
\hline No & 217 & 91.6 & 182 & 84.3 & \\
\hline
\end{tabular}

${ }^{\mathrm{a}}$ Chi-square test.

${ }^{\text {b} F i s h e r ' s ~ e x a c t ~ t e s t . ~}$

'Previous assisted VD, or/and infertility, or/and preterm labor, or/and stillbirth, or/and at least two of the following conditions: miscarriage, extrauterine gravidity, missed abortion, induced abortion due to medical reasons.

increasing trend of deliveries towards the last weekday in case of parous women. Only one-third of deliveries were attended by the obstetrician on duty. Binary logistic regression models explaining delivery outcome with childbirth preference, W-DEQ A score and other factors depicted in Tables 1, 2 and 5, are shown in Table 6. Three variables contributed independently to the binary logistic regression model of nulliparous respondents aimed to explain delivery by CS. A negative contribution 
Table 3. Mid-pregnancy childbirth preferences and mean W-DEQ A scores of nulliparous and parous women.

\begin{tabular}{|c|c|c|c|c|c|}
\hline & \multicolumn{2}{|c|}{$\begin{array}{l}\text { Nulliparous } \\
n=237\end{array}$} & \multicolumn{2}{|l|}{$\begin{array}{l}\text { Parous } \\
n=216\end{array}$} & \multirow[b]{2}{*}{ Significance } \\
\hline & $n /$ mean & $\% / S D$ & n/mean & $\% / S D$ & \\
\hline \multicolumn{6}{|c|}{ Childbirth preference } \\
\hline VD & 220 & 92.8 & 190 & 88 & $p=0.075^{a}$ \\
\hline CS & 12 & 5.1 & 23 & 10.6 & \\
\hline $\begin{array}{l}\text { Undecided/no } \\
\text { response }\end{array}$ & 5 & 2.1 & 3 & 1.4 & \\
\hline W-DEQ A score & 54.9 & 20.2 & 46.2 & 21.1 & $p<0.001^{b}$ \\
\hline
\end{tabular}

$C S$, cesarean section; VD, vaginal delivery; W-DEQ A, Wijma Delivery Expectancy/Experience Questionnaire A.

${ }^{a}$ Chi-square test.

Independent-sample $t$-test.

Table 4. Mode of delivery of nulliparous and parous respondents related to their mid-pregnancy childbirth preferences and mean $\mathrm{W}$ DEQ A scores.

\begin{tabular}{|c|c|c|c|c|c|}
\hline & \multicolumn{2}{|c|}{$\begin{array}{l}\text { VD or assisted } \\
\text { VD }\end{array}$} & \multicolumn{2}{|l|}{ CS } & \multirow[b]{2}{*}{ Significance } \\
\hline & n/mean & $\% / S D$ & $n /$ mean & $\% / S D$ & \\
\hline $\begin{array}{l}\text { Nulliparous } \\
(n=237)\end{array}$ & $n=142$ & & $n=95$ & & \\
\hline \multicolumn{6}{|c|}{ Childbirth preference } \\
\hline VD & 134 & 94.4 & 86 & 90.5 & $p=0.262^{a}$ \\
\hline $\begin{array}{l}\text { CS/undecided/no } \\
\text { response }\end{array}$ & 8 & 5.6 & 9 & 9.5 & \\
\hline W-DEQ A score & 54.3 & 20.1 & 55.7 & 20.5 & $p=0.583^{b}$ \\
\hline Parous $(n=216)$ & $n=160$ & & $n=56$ & & \\
\hline \multicolumn{6}{|c|}{ Childbirth preference } \\
\hline VD & 153 & 95.6 & 37 & 66.1 & $p<0.001^{a}$ \\
\hline $\begin{array}{l}\text { CS/undecided/no } \\
\text { response }\end{array}$ & 7 & 4.4 & 19 & 33.9 & \\
\hline W-DEQ A score & 43.8 & 21.5 & 52.9 & 18.5 & $p=0.005^{b}$ \\
\hline
\end{tabular}

$C S$, cesarean section; VD, vaginal delivery; W-DEQ A, Wijma Delivery Expectancy/Experience Questionnaire A.

${ }^{a}$ Chi-square test.

${ }^{b}$ Independent-sample $t$-test.

of the principal component "Being in control" and a positive impact of a longer perceived pregnancy decision to conception interval and the attending obstetrician's power to decide upon CS was detected. In the third step, the goodness-of-fit was 0.11 . The model for parous respondents showed much higher goodness-of-fit (0.43). The variables that had a significant positive impact were the principal components " $\mathrm{CS}$ is more beneficial than VD" and "Environmental influence" and the age of the attending obstetrician, whereas age of the respondent contributed negatively to the model describing delivery by CS.
Table 5. Supplementary obstetric outcome data regarding time of delivery and the attending obstetrician.

\begin{tabular}{|c|c|c|c|c|c|}
\hline & \multicolumn{2}{|c|}{$\begin{array}{l}\text { Nulliparous } \\
n=237\end{array}$} & \multicolumn{2}{|c|}{$\begin{array}{l}\text { Parous } \\
n=216\end{array}$} & \multirow[b]{2}{*}{ Significance } \\
\hline & $n$ & $\%$ & $n$ & $\%$ & \\
\hline \multicolumn{6}{|l|}{ Time of day } \\
\hline $07.00-15.00 \mathrm{~h}$ & 111 & 46.8 & 87 & 40.3 & \multirow[t]{3}{*}{$p=0.155$} \\
\hline $15.00-23.00 \mathrm{~h}$ & 71 & 30.0 & 62 & 28.7 & \\
\hline $23.00-07.00 \mathrm{~h}$ & 55 & 23.2 & 67 & 31.0 & \\
\hline \multicolumn{6}{|l|}{ Day of week } \\
\hline Monday & 41 & 17.3 & 21 & 9.7 & \multirow[t]{7}{*}{$p=0.020$} \\
\hline Tuesday & 46 & 19.4 & 28 & 13.0 & \\
\hline Wednesday & 26 & 11.0 & 34 & 15.7 & \\
\hline Thursday & 26 & 11.0 & 40 & 18.5 & \\
\hline Friday & 40 & 16.9 & 44 & 20.4 & \\
\hline Saturday & 27 & 11.4 & 21 & 9.7 & \\
\hline Sunday & 31 & 13.1 & 28 & 13.0 & \\
\hline \multicolumn{6}{|c|}{ Patient's own obstetrician at delivery } \\
\hline Yes & 160 & 67.5 & 145 & 67.1 & \multirow[t]{2}{*}{$p=0.931$} \\
\hline No & 77 & 32.5 & 71 & 32.9 & \\
\hline \multicolumn{6}{|c|}{ Attending obstetrician's power to decide on delivery } \\
\hline Yes & 152 & 64.1 & 132 & 61.1 & \multirow[t]{2}{*}{$p=0.506$} \\
\hline No & 85 & 35.9 & 84 & 38.9 & \\
\hline \multicolumn{6}{|c|}{ Gender of attending obstetrician } \\
\hline Male & 148 & 62.4 & 141 & 65.3 & \multirow[t]{2}{*}{$p=0.531$} \\
\hline Female & 89 & 37.6 & 75 & 34.7 & \\
\hline \multicolumn{6}{|c|}{ Age of attending obstetrician } \\
\hline $20 \mathrm{~s}$ & 22 & 9.3 & 30 & 13.9 & \multirow[t]{6}{*}{$p=0.061$} \\
\hline $30 \mathrm{~s}$ & 140 & 59.1 & 108 & 50.0 & \\
\hline $40 \mathrm{~s}$ & 34 & 14.3 & 46 & 21.3 & \\
\hline $50 \mathrm{~s}$ & 16 & 6.8 & 9 & 4.2 & \\
\hline $60 \mathrm{~s}$ & 24 & 10.1 & 19 & 8.8 & \\
\hline $70 \mathrm{~s}$ & 1 & 0.4 & 4 & 1.9 & \\
\hline
\end{tabular}

This study aimed to unfold non-medical factors contributing to different modes of delivery in one of the five university obstetric departments of a Central European country characterized by high CS rates. We analyzed nonhigh-risk pregnant women's socio-demographic features, childbirth-related attitudes, fears and preferences and the circumstances in which subsequent deliveries took place.

Our results that nulliparous women tended to have higher W-DEQ A scores than their parous counterparts are equivocal with international findings (19-21). However, neither the W-DEQ A score (which addresses fear of childbirth), nor the women's preference for delivery, predicted delivery outcome. Although bivariate analysis revealed a correlation between both preference for childbirth and W-DEQ A score and delivery outcome in the case of parous women, neither of these factors entered the logistic regression models, suggesting that women's 
Table 6. Multiple logistic regression models by forward conditional variable selection method explaining mode of delivery.

\begin{tabular}{|c|c|c|c|c|c|c|c|c|}
\hline \multicolumn{9}{|l|}{ Nulliparous $(n=237)$} \\
\hline Significance & & & 0.000 & & 0.000 & & & 0.000 \\
\hline Nagelkerke $R^{2}$ & & & 0.051 & & 0.084 & & & 0.110 \\
\hline Variables & Significanc & & $\operatorname{Exp}(B)$ & Significance & $\operatorname{Exp}(B)$ & & Significance & $\operatorname{Exp}(B)$ \\
\hline $\begin{array}{l}\text { The obstetrician's power to } \\
\text { decide on CS }\end{array}$ & 0.003 & & 2.295 & 0.004 & 2.229 & & 0.008 & 2.125 \\
\hline $\begin{array}{l}\text { Perceived decision-to-conception } \\
\text { interval }\end{array}$ & & & & 0.013 & 2.023 & & 0.014 & 2.022 \\
\hline $\begin{array}{l}\text { Principal component } \\
\text { "Being in control" }\end{array}$ & & & & & & & 0.029 & 0.714 \\
\hline \multicolumn{9}{|l|}{ Parous $(n=216)$} \\
\hline Significance & & 0.000 & & 0.000 & & 0.000 & & 0.000 \\
\hline Nagelkerke $R^{2}$ & & 0.336 & & 0.382 & & 0.409 & & 0.430 \\
\hline Variables & Significance & $\operatorname{Exp}(B)$ & Significance & $\operatorname{Exp}(B)$ & Significance & $\operatorname{Exp}(B)$ & Significance & $\operatorname{Exp}(B)$ \\
\hline $\begin{array}{l}\text { Principal component "CS is more } \\
\text { beneficial than VD" }\end{array}$ & 0.000 & 3.176 & 0.000 & 3.260 & 0.000 & 3.492 & 0.000 & 2.527 \\
\hline Age of the attending obstetrician & & & 0.003 & 1.576 & 0.001 & 1.694 & 0.004 & 1.598 \\
\hline Age (in years) & & & & & 0.022 & 0.905 & 0.023 & 0.905 \\
\hline $\begin{array}{l}\text { Principal component } \\
\text { "Environmental influence" }\end{array}$ & & & & & & & 0.040 & 1.613 \\
\hline
\end{tabular}

Logistic regression, forward conditional method. Dependent variable: mode of delivery $0=$ VD or assisted VD; $1=C S$. Independent variables: Principal component "Being in control"; Principal component "Right to autonomy"; Principal component "In close contact with the newborn"; Principal component "Trust in the natural way"; Principal component "Environmental influence"; Principal component "CS is more beneficial than VD"; Principal component "Expectations toward maternity care"; Principal component "VD, the object of fear"; W-DEQ A score; level of education (in years); place of residence; self-rated financial status; tobacco habits; age (in years); civil status; planned pregnancy; perceived decision-toconception interval; mode of fertilization; complications in obstetric history; childbirth preference; gestational age; time of day of delivery; day of week of delivery; patient's own obstetrician attending delivery; obstetrician's power to decide on CS; gender of the attending obstetrician; age of the attending obstetrician.

CS, cesarean section; VD, vaginal delivery; W-DEQ A, Wijma Delivery Expectancy/Experience Questionnaire A.

fears or preferences were not independent contributors to the actual delivery outcome. There has been an ongoing debate on whether a high level of antenatal FOC or antenatal preference for CS can be related to obstetric complications such as emergency CS or ventouse/forceps delivery. In a Swedish sample of women, Ryding et al. (6) found that FOC measured in the third trimester was associated with emergency CS due to imminent fetal asphyxia. The same association was detected by Laursen et al. (7) in a Danish cohort of healthy nulliparous women; however, the link was dystocia or protracted labor, not fetal distress (7). Antenatal preference for CS, maternal age and previous CS independently predicted elective and emergency CS in an unselected Swedish sample (22). In contrast, Johnson and Slade found nulliparity, presence of medical risk factors, previous CS and maternal anticipation of CS, but not antenatal FOC to be predictive of emergency CS in an unselected UK sample (19). Although Fenwick et al. (20) found an association between antenatal FOC and emergency CS in healthy pregnant Australian women, the association disappeared after adjustment for nulliparity and fetal compromise (20). The latter authors suggest that in countries where midwifery and obstetrics manage a relative equilibrium, the reality of the needs and fears of women can emerge. On the other hand, in maternity care models where power inequality among professionals is obvious and private obstetric care complicates the scene, the effect of women's attitudes may be played down by other factors. They also conclude that differently conceptualized childbirth and its effect on maternity care policies might be found against the background of different CS rates of countries, rather than individual maternal factors such as FOC (20). Nonetheless, Sluijs et al. (21) could not reveal any correlation between FOC and delivery outcome in a Dutch cohort of healthy women with low-risk pregnancies (21).

Although higher W-DEQ A scores and mid-pregnancy maternal childbirth preferences did not contribute to the logistic regression models explaining obstetric outcome in our sample of women, some maternal attitudes did enter the models. Whereas the principal component "Environmental influence" referred to an extrinsic pressure on 
parous women (especially with previous CS) not to be involved in $\mathrm{VD}$, the principal component " $\mathrm{CS}$ is more beneficial than VD" certified an intrinsic belief that CS was the more advantageous and less dangerous of the two options. On the other hand, it seems that higher scores reached by nulliparous women with the principal component "Being in control" were "protective" against CS. The complementary phenomenon was described by Haines et al. (8): Australian and Swedish women in the "Take it as it comes" group were not afraid of delivery, but had no firm preference for type of birth; therefore they were more likely to accept obstetric interventions when those were phrased as being for the well-being of the child (8).

In our survey, one of the most important objective predictors of subsequent delivery by CS detected in midpregnancy was the perceived interval of more than six months between the decision to try for pregnancy and conception in the case of nulliparous respondents. A longer pregnancy decision-to-conception interval can enhance the "precious baby" concept for both women and obstetricians. Kingdon et al. claim that the concept of maternal choice regarding mode of birth is challenged by many different factors: personal preference is not that important in view of safety concerns (13). Obstetricians, on the other hand, are likely to approach "precious" pregnancies in a defensive way in order to avoid malpractice litigation. Walker et al., who investigated thresholds of patients and their caregivers toward fetal risk, found that both groups of respondents had a low tolerance for fetal risk associated with VD (23). Women in a medicalized model of care were less tolerant compared with those involved in lower intervention models, or as the authors put it "these women may have lowered their expectations for vaginal birth" (23). It seems that the type of health care provider does play a role in the perception of benefits or risks of different types of delivery; thus different groups of women are exposed to different kinds of information, with emphasis placed on different issues (24-26). Alternatively, in terms of attitudes towards birth technology, different, self-selecting populations of pregnant women resort to different forms of maternity care (26). Either way, the phenomenon of over-estimation of risks in pregnancy seems to drive both women and obstetricians to engage in even riskier procedures (27).

The possible role of convenience and financial incentives for obstetricians emerges especially in countries with high CS rates. Potter et al. (12) found that the huge difference between CS rates of private and public obstetric patients in Brazil could not be explained by the difference in their preferences for delivery, since it was not significant. They offered three explanations instead: (i) private doctors were truly convinced that CS was more beneficial for patients; (ii) they were not receptive enough to find out what their patients really wanted, and simply assumed it was elective CS. The third possible explanation (iii) was that scheduled CSs provided better time management than unpredictable VDs for busy obstetricians. Entirely different aspects of private practice were highlighted by Abenhaim et al. (28), who found that Canadian on-call obstetricians were more likely than the patients' own doctors to rush to the operating theater in case of suspected fetal compromise. The explanation for the finding given by the authors was the protective role of a good doctorpatient relationship against malpractice lawsuits. Gyarmati et al. (2) investigated whether timing of deliveries or the age of the attending obstetrician contributed to the CS rates in one hospital in Budapest, the capital of Hungary. They found that CSs were more frequent on workdays and before major holidays, in June and December, but the personal factors did not contribute to the rising CS rates. All the above-mentioned phenomena are good examples of non-medical factors influencing medical willingness to intervene.

In contrast with these findings, neither private practice nor timing contributed significantly to the model describing the mode of subsequent delivery in multivariate analysis. Two factors related to the attending obstetricians, however, played an important role, namely (i) their power to decide on CS in the case of nulliparous women and (ii) their own age in case of parous women. It is unlikely that Hungarian obstetricians are not receptive to the patients' preferences, given the continuous personal care provided throughout pregnancy in the majority of the cases. Although having the power to decide on CS can provide better time management for a professional, it also means that he or she bears all responsibility in an obstetric situation to deliver the "perfect outcome", which might lead to defensive acts. Older age and more experience of the attending obstetrician can also lead to a certain cautiousness in borderline cases.

One surprising factor needs to be highlighted that prevented parous women from delivering by CS: older age. Older maternal age has been a traditional argument for rising CS rates (22), but in this survey we detected the opposite role of age. It seems that the biological effect of aging on the body of women was balanced by other, most probably cultural, factors.

The majority of women in this study consistently preferred VD antenatally; however, one-third of them delivered by CS. "The number of women preferring or requesting a CS is far fewer than the number of women receiving the procedure", Gamble et al. (9) concluded in referring to their previous review of CS on maternal request, and thus doubted that the available research established the true role of women's requests in maintaining high CS rates. Potter et al. found that there were large 
numbers of Brazilian private patients who underwent unwanted CS (11). Seven years later they showed that the proportion of certain medical indications (such as malpresentations) reported by private patients who underwent CS was higher than that in the public sector. They highlighted that a liberal attitude towards CS "could reduce rather than increase the chances women have to achieve their preferred type of delivery" (12).

It needs to be emphasized that we refrain from comparing our results with those of other studies investigating the association between level of FOC and subsequent delivery outcome, since the Hungarian translation of $\mathrm{W}$ DEQ A has not yet been validated. Furthermore, questionnaires in most of these studies were completed in the last trimester, whereas our questionnaires were completed in mid-pregnancy.

Since around one-third of respondents delivered by CS, which is the same CS rate as the national one, we assume that data given in this article are generalizable to the pregnant population in the country. To minimize the effect of medical factors, we excluded women known to be highrisk already at mid-pregnancy, and those who were wellinformed about anticipating CS for medical reasons (with the exception of women with previous CS). The relative weakness of the logistic regression model explaining delivery outcome of nulliparous women suggested that other factors not investigated in this study (most likely medical ones) make a comparably larger contribution to the subsequent delivery outcome in their case. On the other hand, the relative strength of the model for parous women highlighted that in their case, medical factors can easily become overshadowed by other aspects.

\section{Conclusion}

In this survey, a relatively large contribution of nonmedical factors was identified against the background of CSs. Mid-pregnancy preference for CS and higher WDEQ A scores were not the most important of these. Our findings contribute to the already existing evidence that in countries with high CS rates, the role of non-medical factors, related as much to obstetricians as to pregnant women's preferences or fears, should be considered.

\section{Funding}

No specific funding.

\section{Acknowledgments}

The Hungarian translation of the W-DEQ A was performed by one of the authors (D.D.) with the approval of the copyright holder, Prof. Klaas Wijma.

\section{References}

1. Tauffer Database. National Institute for Quality- and Organizational Development in Healthcare and Medicine. Available online at: http://193.225.50.35/webgy/regbe/ belepes.php. (accessed March 24, 2014).

2. Gyarmati B, Nagy P, Tiba J. A császármetszések gyakoriságának változása és néhány feltételezett ok elemzése az Uzsoki utcai kórházban 1999. január 1. és 2009. június 30. között. [Trends in prevalence of caesarean section in Uzsoki Hospital between 1 January 1999 and 30 June 2009. Analysis of some suspected factors.] (in Hungarian) Magy Noorv L. 2009;72:269-72.

3. Coleman VH, Lawrence H, Schulkin J. Rising cesarean delivery rates. The impact of cesarean delivery on maternal request. Obstet Gynecol Surv. 2009;64:115-9.

4. Habiba M, Kaminski M, Da Fré M, Marsal K, Bleker O, Librero J, et al. Caesarean section on request: a comparison of obstetricians' attitudes in eight European countries. BJOG. 2006;113:64756.

5. Weaver JJ, Statham H, Richards M. Are there "unnecessary" cesarean sections? Perceptions of women and obstetricians about cesarean sections for nonclinical indications. Birth. 2007;34:37-41.

6. Ryding EL, Wijma B, Wijma K, Rydhström H. Fear of childbirth during pregnancy may increase the risk of emergency cesarean section. Acta Obstet Gynecol Scand. 1998;77:542-7.

7. Laursen M, Johansen C, Hedegaard M. Fear of childbirth and risk for birth complications in nulliparous women in the Danish National Birth Cohort. BJOG. 2009;116:1350-5.

8. Haines HM, Rubertsson C, Pallant JF, Hildingsson I. The influence of women's fear, attitudes and beliefs on mode and experience of birth. BMC Pregnancy Childbirth. 2012;12:55.

9. Gamble J, Creedy DK, McCourt C, Weaver J, Beake S. A critique of the literature on women's request for cesarean section. Birth. 2007;34:331-40.

10. Rebelo F, Da Rocha CMM, Cortes TR, Dutra CL, Kac G. High cesarean prevalence in a national population-based study in Brazil: the role of private practice. Acta Obstet Gynecol Scand. 2010;89:903-8.

11. Potter JE, Berquó E, Perpétuo IH, Leal OF, Hopkins K, Souza MR, et al. Unwanted caesarean sections among public and private patients in Brazil: prospective study. BMJ. 2001;323:1155-8.

12. Potter JE, Hopkins K, Faúndes A, Perpétuo I. Women's autonomy and scheduled cesarean sections in Brazil: a cautionary tale. Birth. 2008;35:33-40.

13. Kingdon C, Neilson J, Singleton V, Gyte G, Hart A, Gabbay M, et al. Choice and birth method: mixed-method study of caesarean delivery for maternal request. BJOG. 2009;116:886-95. 
14. Gaál P, Szigeti Sz, Panteli D, Gaskins M, van Ginneken E. Major challenges ahead for Hungarian healthcare. BMJ. 2011;343:1251-4.

15. Dweik D, Girasek E, Töreki A, Mészáros G, Pál A. Women's antenatal preferences for delivery route in a setting with high cesarean section rates and a medically dominated maternity system. Acta Obstet Gynecol Scand. 2014;93:408-15.

16. Papp Z. A Szülészeti és Nogyógyászati Szakmai Kollégium 2003. Február 28-i állásfoglalása a császármetszések arányának alakulásával és a további emelkedés kívánatos megelozésével kapcsolatban. [The official position of the Hungarian College of Obstetrics and Gynecology regarding the proportion of caesarean sections and the prevention of further rise in caesarean section rate.] (in Hungarian. No abstract available.) Magy Noorv L. 2003;66:191-2.

17. Wijma K, Wijma B, Zar M. Psychometric aspects of the W-DEQ; a new questionnaire for the measurement of fear of childbirth. J Psychosom Obstet Gynaecol. 1998;19:8497.

18. Field A. Discovering statistics using SPSS. London: SAGE Publications, 2005.

19. Johnson R, Slade P. Does fear of childbirth during pregnancy predict emergency caesarean section? BJOG. 2002;109:1213-21.

20. Fenwick J, Gamble J, Nathan E, Bayes S, Hauck Y. Pre- and postpartum levels of childbirth fear and the relationship to birth outcomes in a cohort of Australian women. J Clin Nurs. 2009;18:667-77.
21. Sluijs AM, Cleiren MP, Scherjon SA, Wijma K. No relationship between fear of childbirth and pregnancy-/ delivery-outcome in a low-risk Dutch pregnancy cohort delivering at home or in hospital. J Psychosom Obstet Gynecol. 2012;33:99-105.

22. Hildingsson I. How much influence do women in Sweden have on caesarean section? A follow-up study of women's preferences in early pregnancy. Midwifery. 2008;24:46-54.

23. Walker SP, McCarthy EA, Ugoni A, Lee A, Lim S, Permezel M. Cesarean delivery or vaginal birth. A survey of patient and clinician thresholds. Obstet Gynecol. 2007;109:67-72.

24. Reime B, Klein MC, Kelly A, Duxbury N, Saxell L, Liston $\mathrm{R}$, et al. Do maternity care provider groups have different attitudes towards birth? BJOG. 2004;111:1388-93.

25. Monari F, di Mario S, Fachinetti F, Basevi V. Obstetricians' and midwives' attitudes toward cesarean section. Birth. 2008;35:129-35.

26. Klein MC, Kaczorowski J, Hearps SJ, Tomkinson J, Baradaran N, Hall WA, et al. Birth technology and maternal roles in birth: knowledge and attitudes of Canadian women approaching childbirth for the first time. J Obstet Gynaecol Can. 2011;33:598-608.

27. Robinson M, Pennell CE, Mclean NJ, Oddy WH, Newnham JP. The over-estimation of risk in pregnancy. J Psychosom Obstet Gynecol. 2011;32:53-8.

28. Abenhaim HA, Benjamin A, Koby RD, Kinch RA, Kramer MS. Comparison of obstetric outcomes between on-call and patients' own obstetricians. CMAJ. 2007;177:352-73. 